\title{
The dual degree orthopedic surgeon: A survey of the trends, motivations, and perceived value of the master of business administration degree
}

\author{
William F. Sherman, MD, MBA ${ }^{1}$, Sean C. Clark, MS ${ }^{1}$, Victor J. Wu, MD', Hunter L. Bohlen, MD, MBA ${ }^{1}$, Olivia C. Lee, MD $^{2}$ \\ 1 Department of Orthopaedic Surgery, Tulane University School of Medicine, ${ }^{2}$ Department of Orthopaedics, Louisiana State University Health \\ Sciences Center School of Medicine \\ Keywords: business, dual degree, orthopaedic surgery, mba
}

https://doi.org/10.52965/001c.24384

\section{Orthopedic Reviews}

Vol. 13, Issue 1, 2021

\begin{abstract}
Orthopedic surgeons are obtaining Master of Business Administration (MBA) degrees at an increasing rate. This study aimed to identify the motivations, trends, and perceived value of the MBA degree for these dual degree surgeons. A total of 157 orthopedic surgeons with both MD and MBA degrees were surveyed with a 19-item questionnaire to identify surgeons' motivations for obtaining an MBA degree and the perceived value of the degree. A total of 66 responses (42\%) were received. Most respondents (89.4\%) viewed the MBA degree as either extremely valuable or valuable. Prior to obtaining an MBA, $71.9 \%$ of dual degree surgeons dedicated time to administrative duties outside of the clinic. This number increased to $98.4 \%$ after receiving an MBA $(p<0.001)$. With the growing number of surgeons pursuing MBA degrees, there is a decrease in the time spent in the clinical role suggesting that either the non-clinical burden is increasing, or surgeons choose to re-allocate their time. Despite the high direct costs of an MBA, a majority of orthopedic surgeons perceived the MBA degree as a valuable investment they would pursue again.
\end{abstract}

\section{INTRODUCTION}

Cost and quality have become significant decision-making drivers in the delivery of healthcare over the past several decades. ${ }^{1}$ As the pressure of cost containment and efficiency optimization has intensified, some physicians have become more involved in the business of healthcare while some are leaving the profession altogether. ${ }^{2,3}$ Specifically, physicians are becoming owners and administrators of hospitals and leaders of large departments that require business acumen. ${ }^{4}$ Cost and quality are not only being tracked, but these metrics are being tied to reimbursement leading to increased physician focus. 5

Given these new and changing payments and business models, physicians may elect to pursue a Master of Business Administration (MBA) degree. An MBA program focuses globally on business which is translatable to the healthcare industry. ${ }^{6}$ The number of MD/MBA programs has increased from 6 in 1993 to 65 in 2012, and the number of physicians receiving MBA degrees from these programs has increased from 27 in 1999 to 42 in 2000 to 62 in 2001. ${ }^{7,8}$ An MBA program provides financial understanding, accounting principles, leadership skills, and business integration historically not part of a medical school curriculum. ${ }^{9}$ Thus, an MBA de- gree can offer the business skills necessary for physicians to remain competitive within the changing healthcare landscape. ${ }^{9}$

Orthopedic surgeons may be uniquely motivated to pursue an MBA due to significant policy changes targeting musculoskeletal healthcare. ${ }^{10}$ Previous studies have investigated the motivations of physicians obtaining an MBA degree. However, there has been no study specifically aimed at understanding the motivations of orthopedic surgeons obtaining an MBA degree. ${ }^{11,12}$ The purpose of this study was to evaluate the experience of orthopedic surgeons who have obtained an MBA, specifically to document the motivations, trends, and perceived value of the MD/MBA for the orthopedic surgeon.

\section{MATERIALS AND METHODS}

An online, voluntary, self-administered questionnaire was distributed to orthopedic surgeons with dual MD/MBA degrees in the United States. Study participants were recruited from the American Academy of Orthopaedic Surgeons (AAOS) directory and were included if they had both an MD and MBA degree listed in their profiles. Further potential respondents were gathered from publicly available informa- 
tion on online search engines using the same inclusion criteria. A total of 157 orthopedic surgeons were identified. A single email was sent to all potential study participants with a recruitment message, survey link, and consent script. The survey included 19 questions divided into three sections: subjective questions, objective questions, and demographics (Appendix A). Personal questions included orthopedic surgeons' motivations for obtaining an MBA degree and whether they thought the MBA was valuable. Objective questions addressed the costs associated with obtaining the degree, how surgeons' clinical and administrative duties changed as a result of the degree, and the impact of the degree on surgeons' compensation. Respondents who reported a change in compensation during medical school or residency after obtaining an MBA were not included in the analysis of surgeons' salaries. All email and survey contents were reviewed by the institutional review board (IRB), and the study was granted IRB review exemption.

Of the 157 orthopedic surgeons with dual MD/MBA degrees, a total of 66 responses (42\%) were received. A few respondents (6 of $66,9.1 \%$ ) only partially completed the survey. Most of the respondents were male (65 of $66,98.4 \%$ ). Responses were compared using chi-square analysis with Yate's correction and Fisher's exact test for categorical variables. Statistical analysis was performed using SAS 9.4 (SAS Institute, Cary, NC, USA) with an $\alpha$ level set at 0.05 .

\section{RESULTS}

\section{MOTIVATIONS AND PERCEIVED VALUE OF AN MBA DEGREE}

The top reasons for why respondents obtained an MBA degree were to learn more about the business of healthcare (30 of $66,45.5 \%$ ), to survive in the changing healthcare system (15 of $66,22.7 \%$ ), and to seek promotion within the hospital system (4 of 66, 6.1\%) (Table 1). Most surgeons viewed the MBA degree as either extremely valuable (28 of $66,42.4 \%$ ) or valuable (31 of $66,47 \%$ ), leaving $7.6 \%$ (5 of 66 ) who viewed their MBA as somewhat valuable and $3.0 \%$ (2 of 66 ) who viewed their MBA with little or no value (Figure 1). The perceived value of the degree was similar for those who received the degree while in practice in comparison to those who obtained the degree as a student or resident (3.36 vs. $3.10)$ ( $p=0.298$ ). Ninety-two percent (61 of 66 ) of respondents felt that getting an MBA was a great idea, and 50.8\% (33 of 65) agreed that having an MBA has helped them in their current occupational role.

The primary motivation for choosing the school from which they obtained an MBA degree was convenience (32 of $66,48.5 \%$ ), while the prestige of the program was secondary (17 of $66,25.8 \%$ ). Most surgeons obtained the degree through an in-person classroom setting (48 of 66, $72.7 \%$ ) rather than from an online program ( 9 of $66,13.6 \%$ ). There was no statistical significance in a subspecialty for those who obtained the degree ( $\underline{\text { Table } 2}$ ).

\section{CLINICAL AND ADMINISTRATIVE DUTIES}

Prior to obtaining an MBA degree, 28.1\% (18 of 64) of orthopedic surgeons spent $100 \%$ of their time on clinical respon-
Table 1. Top motivations for orthopedic surgeons pursuing an MBA degree.

\begin{tabular}{|c|}
\hline Motivations for an MBA Degree \\
\hline 1. Learning more about the Healthcare Business (45.5\%) \\
\hline 2. Surviving in a changing Healthcare System (22.7\%) \\
\hline 3. Seeking Promotion within the Hospital System (6.1\%) \\
\hline
\end{tabular}

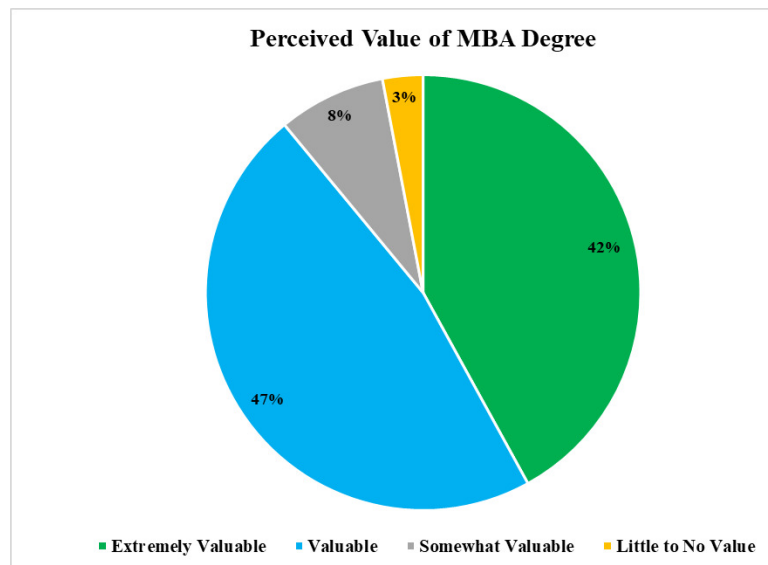

Figure 1. Orthopedic surgeons' perceived value of the MBA degree.

Table 2. Subspecialties of orthopedic surgeons with MBA degrees.

\begin{tabular}{|c|c|}
\hline \multicolumn{2}{|c|}{ Subspecialties of Orthopaedic Surgery } \\
\hline Joints & $23.4 \%$ \\
\hline Spine & $14.1 \%$ \\
\hline Hand & $10.9 \%$ \\
\hline Trauma & $10.9 \%$ \\
\hline General & $9.4 \%$ \\
\hline Sports & $9.4 \%$ \\
\hline Pediatrics & $7.8 \%$ \\
\hline Shoulder \& Elbow & $6.3 \%$ \\
\hline Foot \& Ankle & $4.7 \%$ \\
\hline Musculoskeletal Oncology & $3.1 \%$ \\
\hline
\end{tabular}

sibilities. After completion of an MBA program, this number decreased to $1.6 \%$ ( 1 of 64 ) ( $\mathrm{p}<0.001$ ). Prior to obtaining an MBA, $32.8 \%$ (21 of 64 ) of surgeons allocated $90 \%$ of the time to clinical duties and $10 \%$ to administrative duties. After obtaining an MBA, this number decreased to 20.3\% (13 of 64) $(\mathrm{p}=0.265)$ (Figure 2). Time spent on administrative responsibilities increased for $46.9 \%$ (30 of 64) of surgeons, and there was an average $12.0 \%$ decrease in clinical work after receiving an MBA. 


\section{COSTS AND RETURN ON INVESTMENT}

The total cost of the MBA was variable with $4.5 \%$ paying no cost (3 of 66), 30.3\% (20 of 66) paying between $\$ 0-\$ 50,000$, $30.3 \%$ (20 of 66 ) paying between $\$ 50,000-\$ 100,000,18.2 \%$ (12 of 66 ) paying between $\$ 100,000-\$ 150,000$, and $16.7 \%$ (11 of 66 ) paying greater than $\$ 150,000$. The average cost for those who pursued the degree as a student or resident $(\$ 59,211)$ was significantly lower in comparison to those who obtained the degree while they were already in practice $(\$ 91,489)(p=0.016)$. The majority paid for the degree outof-pocket (51 of $66,77.3 \%$ ), while others received sponsorship from their institution ( 9 of 66, 13.6\%).

Most orthopaedic surgeons (34 of 66, 51.5\%) said there was no opportunity cost in obtaining an MBA degree, while $16.7 \%$ (11 of 66 ) reported between a $\$ 0-\$ 50,000$ loss, $4.5 \%$ (3 of 66 ) reported between a $\$ 50,000-\$ 100,000$ loss, $7.6 \%$ (5 of 66 ) reported between a $\$ 100,000-\$ 150,000$ loss, and $19.7 \%$ (13 of 66) reported greater than a $\$ 150,000$ loss (Figure 3). Additionally, opportunity cost was lower for those in practice in comparison to those who pursued the degree as students $(\$ 39,095$ vs. $\$ 81,589)(p=0.050)$.

While most respondents (40 of $63,63.5 \%$ ) reported no change in salary after obtaining the degree, $7.9 \%$ (5 of 63 ) reported a $\$ 0-\$ 50,000$ increase, $3.2 \%$ (2 of 63 ) reported a $\$ 50,000-\$ 100,000$ increase, $6.3 \%$ (4 of 63) reported a $\$ 100,000-150,000$ increase, $15.9 \%$ (10 of 63 ) reported greater than a $\$ 150,000$ increase in salary, and $3.2 \%$ (2 of 63) reported a decrease in salary. There was no significant difference in the employment status of surgeons before and after obtaining an MBA.

\section{TIMING OF MBA EDUCATION}

There was a 29-year span of when responders obtained their MBA degrees (1990-2019), but a majority received the degree from 2010 to 2019 (42 of 63, 66.6\%). The time for completion of an MBA program ranged between 1 and 3 years, with most completing the program in 2 years (32 of $66,48.5 \%)$. Students and residents took an average of 20.8 months to receive the degree, while those in practice took 24.3 months $(\mathrm{p}=0.142)$.

\section{DISCUSSION}

This study aimed to understand the motivations, effects, and perceived value of the MBA degree for dual degree orthopedic surgeons. The most common explanation to obtain an MBA was to learn more about the business of healthcare (45.5\%) (Table 1). While some of these respondents may have been motivated to improve their practices, the focus on learning more about the healthcare business may be largely due to the changing healthcare system.

Orthopedic procedures have become a target of policy change due to the high volume and costs associated with musculoskeletal healthcare. ${ }^{10}$ There were several significant catalysts for this change. The 2010 Affordable Care Act (ACA) set three primary goals: to support an innovative medical care delivery method designed to lower the cost of healthcare. ${ }^{13}$ The Bundled Payments for Care Improvement (BPCI) initiative began in 2013 and comprised of four

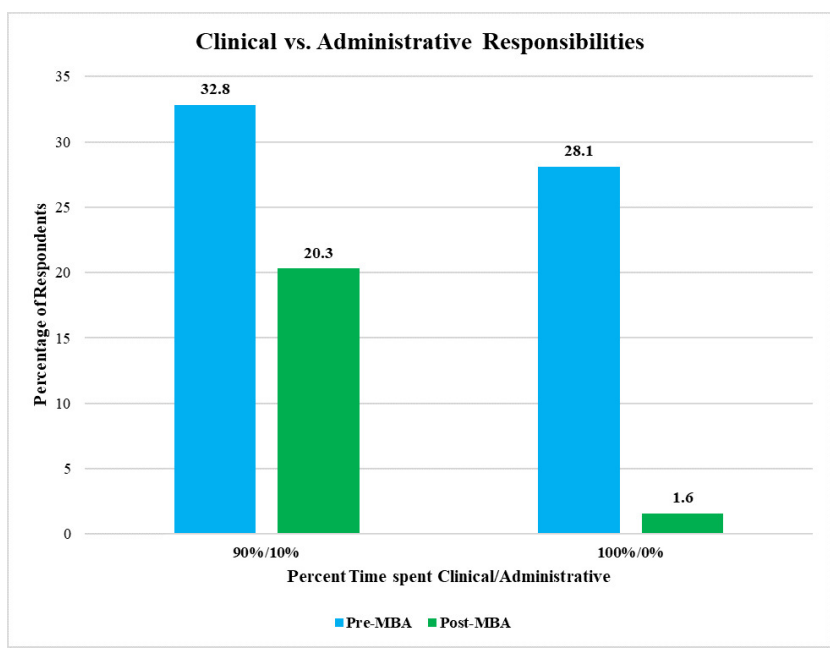

Figure 2. Percent time spent by orthopedic surgeons on clinical and administrative responsibilities before and after obtaining an MBA degree.

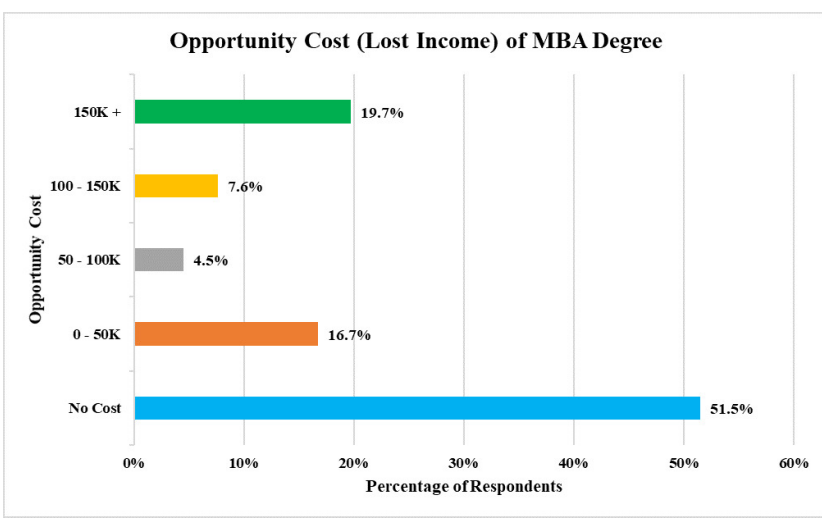

Figure 3. Opportunity cost (lost income) for orthopedic surgeons in obtaining an MBA degree.

broadly defined models of care, which linked payments for the multiple services beneficiaries receive during an episode of care. ${ }^{14}$ The Comprehensive Care for Joint Replacement (CJR) model was implemented in 2016 and aimed to support better and more efficient care for the most common inpatient surgeries for Medicare beneficiaries: hip and knee replacements. ${ }^{15}$ As these initiatives and pressures have increased administrative workload and decreased reimbursement to physicians and facilities, physician burnout has increased, with cost savings becoming a necessary goal. ${ }^{16-20}$ The future uncertainties in healthcare and rising administration challenges may be why most respondents obtained the degree within the past decade (66.6\%).

This study highlights that orthopedic surgeons are actively taking on additional administrative responsibilities with the addition of an MBA. Before obtaining an MBA, $71.9 \%$ of respondents spent a portion of their time on administrative duties. After obtaining an MBA, this number increased to $98.4 \%$ ( $\mathrm{p}<0.001$ ) (Figure 2). Additionally, respondents decreased their clinical duties by an average of $12.0 \%$, and nearly half (46.9\%) reported an increase in the 
amount of time they spent on administrative responsibilities. As a result, dual degree surgeons may be better equipped for handling and therefore more interested in increasing administrative burden. Similarly, Mody et al. examined orthopedic surgeons with MBA degrees and found that $81.1 \%$ were involved in non-clinical work. ${ }^{21}$ Of those involved in non-clinical work, 38.6\% had administrative roles, and $20.5 \%$ were involved in industry consulting. ${ }^{21}$ Lee et al. surveyed plastic surgeons with MBAs and discovered that $73.7 \%$ changed their daily responsibilities after obtaining the degree, $57.9 \%$ gained business roles in addition to their clinical work, and $21.1 \%$ changed careers entirely. ${ }^{22}$ As the musculoskeletal needs of our growing and aging population continue to increase, the trend of practicing physicians decreasing their clinical time is a concern that could be further examined.

The time required for orthopedic surgeons to complete an MBA degree, along with the tuition and the opportunity cost, represents a significant investment. This study demonstrates even with the substantive expenses involved and the variable financial return from the degree, respondents still highly valued their MBA as most viewed the degree as either extremely valuable or valuable (89.4\%) (Figure 1). Similarly, Parekh and Singh found that $81 \%$ of physicians with MBAs believed the degree was helpful in career advancement. ${ }^{11}$ It is important to note that even though most surgeons had no change in salary (63.5\%), a substantial number $(22.2 \%)$ reported a $\$ 100,000$ or greater increase in salary, suggesting the degree could provide a significant financial return. In addition, no respondents obtained the degree at the end of their clinical training just before entering practice, which would have been a significant opportunity cost given the expected substantial increase in compensation at that time.

One key question facing orthopedic surgeons interested in obtaining an MBA is when they should do so. The average cost of a degree was significantly lower for those who obtained the degree as a student or resident $(\$ 59,211)$ versus those who received the degree while they were in practice $(\$ 91,489)(p=0.016)$. This data supports that the up-front financial investment for the MBA degree is lowest for those already in school/residency, demonstrating that dual degree programs offered at many institutions provide value to the students enrolling in them. However, the opportunity cost of getting the degree was lower for those in practice versus those who got the degree as students $(\$ 39,095$ vs. $\$ 81,589)$ $(p=0.050)$. The higher opportunity cost is due to the delay in starting practice at a significantly higher compensation. The \$32,278 average cost savings of obtaining the MBA while a student or resident is weighed against the reported $\$ 42,494$ difference in opportunity cost. However, it is unclear whether the entire opportunity cost of delaying the start of practice by an average of 20.8 months was considered by the respondents. At an average orthopedic surgeon salary of $\$ 511,000$, a delay of 20.8 months represents

\section{$\$ 885,733$ of earnings. ${ }^{23}$}

There are several limitations to the current study. The survey contained only multiple-choice questions, potentially limiting the understanding of the strengths and weaknesses of an MBA. Survey recipients were based on AAOS directory listings and online search, which may have led to selection bias and limited the generalizability of our results. In addition, orthopedic surgeons who were more enthusiastic about their MBA degree may have been more likely to respond to the survey leading to a response bias. Interestingly, $51.5 \%$ of respondents reported no opportunity cost in obtaining an MBA degree (Figure 3). It is unclear whether a delay in earnings or time away from clinical activities was fully included in the respondents' perception of opportunity cost. As most respondents had positive perceptions of the degree, this may represent bias against reporting a negative characteristic such as opportunity cost. Finally, the answer choices to the survey question addressing the opportunity cost of obtaining an MBA were capped at $\$ 150,000$ or greater. If additional choices were provided above $\$ 150,000$, a more accurate average value for opportunity cost could have been obtained.

\section{CONCLUSIONS}

This study shows the MBA has a high perceived value for current dual degree orthopedic surgeons and suggests that the skills learned from these programs can lead to changes in time-allotment, earnings, and capabilities within the healthcare industry. Even with the high financial and opportunity cost of an MBA, a majority of dual degree orthopedic surgeons perceive their MBA degree as a valuable investment they would pursue again.

\section{AUTHOR'S CONTRIBUTIONS}

Sherman - manuscript writing, references search, project outline, data collection

Clark - manuscript writing, references search, data collection

$\mathrm{Wu}$ - manuscript writing

Bohlen - manuscript writing

Lee - manuscript reviewing and editing

\section{DISCLOSURES}

The authors declare no potential conflict of interest.

\section{FUNDING}

None

Submitted: May 07, 2021 EST, Accepted: May 14, 2021 EST 


\section{REFERENCES}

1. Porter ME, Lee TH. The Strategy That Will Fix Health Care. Harvard Business Review. 2013;91(10):50-70.

2. Page AE, Butler CA, Bozic KJ. Factors driving physician-hospital alignment in orthopaedic surgery. Clin Orthop Relat Res. 2013;471(6):1809-1817. doi:1 0.1007/s11999-012-2730-8

3. Landon BE, Reschovsky JD, Pham HH, Blumenthal D. Leaving medicine: the consequences of physician dissatisfaction. Med Care. 2006;44(3):234-242. doi:1 0.1097/01.mlr.0000199848.17133.9b

4. Angood P, Birk S. The value of physician leadership. Physician Exec. 2014;40(3):6-20.

5. Lansky D, Milstein A. Quality measurement in orthopaedics: the purchasers' view. Clin Orthop Relat Res. 2009;467(10):2548-2555. doi:10.1007/s11999-00 9-0999-z

6. Lazarus A. Why an MBA? Physician Exec. $1997 ; 23(8): 41-45$.

7. Larson DB, Chandler M, Forman HP. MD/MBA programs in the United States: evidence of a change in health care leadership. Acad Med. 2003;78(3):335-341. doi:10.1097/00001888-20030300 $\underline{0-00021}$

8. Goyal R, Aung KK, Oh B, Hwang TJ, Besancon E, Jain SH. Survey of MD/MBA Programs: Opportunities for Physician Management Education. Academic Medicine. 2015;90(1):121. doi:10.1097/acm.00000000 $\underline{00000517}$

9. Turner AD, Stawicki SP, Guo WA. Competitive Advantage of MBA for Physician Executives: A Systematic Literature Review. World J Surg. 2018;42(6):1655-1665. doi:10.1007/s00268-017-437 $\underline{0-3}$

10. Dieleman JL, Baral R, Birger M, et al. US Spending on Personal Health Care and Public Health, 1996-2013. JAMA. 2016;316(24):2627-2646. doi:10.10 01/jama.2016.16885

11. Parekh SG, Singh B. An MBA: the utility and effect on physicians' careers. J Bone Joint Surg Am. 2007;89(2):442-447. doi:10.2106/jbjs.F.01245
12. Patel MS, Arora V, Patel MS, Kinney JM, Pauly MV, Asch DA. The role of MD and MBA training in the professional development of a physician: a survey of 30 years of graduates from the Wharton Health Care Management Program. Acad Med. 2014;89(9):1282-1286. doi:10.1097/acm.00000000000 $\underline{00366}$

13. HealthCare.gov. Affordable Care Act (ACA) Published 2010. https://www.healthcare.gov/glossar y/affordable-care-act/

14. Bundled Payments for Care Improvement (BPCI) Initiative. Published 2020. https://innovation.cms.go v/innovation-models/bundled-payments

15. Comprehensive Care for Joint Replacement Model. Published 2020. https://innovation.cms.gov/innovatio n-models/cjr

16. Ames SE, Cowan JB, Kenter K, Emery S, Halsey D. Burnout in Orthopaedic Surgeons: A Challenge for Leaders, Learners, and Colleagues: AOA Critical Issues. J Bone Joint Surg Am. 2017;99(14):e78. doi:10.2 106/jbjs.16.01215

17. Eltorai AEM, Durand WM, Haglin JM, Rubin LE, Weiss AC, Daniels AH. Trends in Medicare Reimbursement for Orthopedic Procedures: 2000 to 2016. Orthopedics. 2018;41(2):95-102. doi:10.3928/01 477447-20180226-04

18. Rao SK, Kimball AB, Lehrhoff SR, et al. The Impact of Administrative Burden on Academic Physicians: Results of a Hospital-Wide Physician Survey. Acad Med. 2017;92(2):237-243. doi:10.1097/ac m.0000000000001461

19. Mayfield CK, Haglin JM, Levine B, Della Valle C, Lieberman JR, Heckmann N. Medicare Reimbursement for Hip and Knee Arthroplasty From 2000 to 2019: An Unsustainable Trend. The Journal of Arthroplasty. Published online 2019. doi:10.1016/j.art $\underline{\text { h.2019.12.008 }}$

20. Sharan AD, Schroeder GD, West ME, Vaccaro AR. Understanding Business Models in Health Care. Clin Spine Surg. 2016;29(4):158-160. doi:10.1097/bsd.0000 $\underline{000000000380}$

21. Mody KS, Acharya PP, Brougham K, Parekh SG. Orthopedic Master's in Business Administration: A career path analysis. Orthopedic reviews. 2019;11(4):8360. doi:10.4081/or.2019.8360 
22. Lee CS, Ooi ASH, Zenn MR, Song DH. The Utility of a Master of Business Administration Degree in Plastic Surgery: Determining Motivations and Outcomes of a Formal Business Education Among Plastic Surgeons. Plast Reconstr Surg Glob Open. 2018;6(6):e1796. doi:10.1097/gox.0000000000001796
23. Kane L. Medscape Physician Compensation Report 2020. Published 2020. https://www.medscap e.com/slideshow/2020-compensation-overview-6012 $684 \# 5$ 


\section{SUPPLEMENTARY MATERIALS}

\section{Appendix A}

Download: https://orthopedicreviews.openmedicalpublishing.org/article/24384-the-dual-degree-orthopedic-surgeona-survey-of-the-trends-motivations-and-perceived-value-of-the-master-of-business-administration-degree/ attachment/61749.docx 